Roth, W.-M., \& Gardner, R. (2012). "They're gonna explain to us what makes a cube a cube?" Geometrical properties as contingent achievement of sequentially ordered child-centered mathematics lessons. Mathematics Education Research Journal, 24, 323-346.

\title{
"They're gonna explain to us what makes a cube a cube?" Geometrical properties as contingent achievement of sequentially ordered child-centered mathematics lessons
}

\begin{abstract}
In mathematics education, there is a continuing debate about the nature of mathematics, which some claim to be an objective science, whereas others note its socially and individually constructed nature. From a strict cultural-historical perspective, the objective and subjective sides of mathematics are but manifestations of a higher order phenomenon that may be summarized by the aphorism that mind is in society to the extent that society is in the mind. In this study, we show, drawing on exemplifying materials from a second-grade unit on three-dimensional geometry, how mathematics manifests itself both as objective science all the while being subjectively produced. A particular three-turn interactional sequence comes to play a central role. We conclude by re-assigning a positive role to a much-maligned sequentially ordered conversational routine. Key words: Vygotsky; Husserl; Cultural re/production; IRE; Conversation analysis; Ethnomethodology; Higher psychological functions; Material relations
\end{abstract}

Any higher psychological function was external; this means that it was social; before becoming a function, it was the social relation between people. The means of acting upon oneself is first a means of acting on others and the action of others on one's personality. In general form: the relation between higher psychological functions once was a material relation between people. (Vygotskij 2005, p. 1021, our translation, original emphasis, bold added) 
What constitutes mathematical knowledge? And how does a child come to know something consistently with mathematics? How are once-new mathematical ideas handed down through generations? In the field of mathematics education, such questions have almost unanimously been answered over the last several decades with discourses grounded in radical/social constructivism, or some other form of constructivism to which such adjectives as sociocultural, cultural-historical, embodied, or enactivist are attached (e.g., Yackel et al. 2011). However, the answer would be radically different from a cultural-historical perspective that takes the Vygotsky of the introductory quotation at his word. He does not say that children do something in a relation with a more advanced peer or teacher and then "construct it for themselves"; rather, in this quotation he writes that what was a material relation first subsequently becomes a psychological function. That is, knowing first exists in and as the material relation; subsequently, it shows up in ways such that it may be attributed to individuals and their higher psychological functions. It is this plane of higher function that develops as children participate in mathematics-oriented social/material relations - rather than stuff that is internalized (or internally constructed) after having been socially constructed (Leont'ev 1983; Lerman 1998). If this is the case, then doing mathematics education research to answer the introductory questions means looking for relations in which children are participants for a first time. It is precisely these relations that one finds subsequently again in the absence of a teacher, for example, between two children who both participated when the relation first occurred.

The purpose of this paper is to exhibit, in concrete material detail, the emergence of geometrical properties and classifications in and as social/materialrelations in which children are an integral part. The particular curricular topic, properties and classifications of three-dimensional objects, is at a level of complexity that existing theories, including Piaget's and van Hiele's, have 
suggested as encompassing conceptions that are too advanced for 6-7-year old children (Roth and Thom 2009a). Piaget and van Hiele, however, thought about individuals. In this article, we suggest that children are enabled to learn this topic precisely because geometrical properties and classifications come to exist concretely and objectively in/as relations of which the children are part. It is in and as this participation that the historical handing-down process consists. Geometry as objective science will have had a history precisely because these forms of social/material relations are produced over and over again.

\section{Toward an ethnomethodological grounding of the cultural-historical approach}

In the opening quotation, Vygotsky talks about higher psychological functions from an after-the-fact adult perspective, where a present day psychological function was a psychological function at some time in the past. We can also turn the perspective around and say that at each time in the life of a child, what is a social/material relation with others today will be a psychological function tomorrow. Thus, when we follow children in the course of their development, we may actually observe their first participations in social/material relations that subsequently will be attributed to their minds. Evidently, however, if they participate in these relations, because relations are bipartisan, the very cognitive functions must be present already on this first occasion. This point has not been sufficiently appreciated in the mathematics education literature that draws on Vygotsky's concept of the zone of proximal development, leaving open how something existing on the outside actually comes to be "internalized" (e.g., Lerman 2000; Roth and Radford 2010). It is precisely because children are participating in a social/material relation today, where mathematical perceptions and coherences are produced that they will reproduce the required perceptions and coherences tomorrow. 
In our work concerned with individual learning and cultural reproduction of geometry, therefore, we are interested in exhibiting and making "instructably observable the local endogenous production and natural accountability of immortal familiar society's most ordinary organizational things in the world" (Garfinkel 1996, p. 6). In this quotation, the author makes salient several crucial points. First, social order is locally produced from within society; and this production itself is not something special but ranks among the most ordinary things people do. In their productions, participants are "naturally" accountable for what they do; this leads to the fact that observing the social structure is something we can be instructed in. In fact, our participation in a social event is equivalent to learning, each time a little more, to enact social structure. With respect to mathematics education, children do not merely find themselves in mathematics lessons, as if these were prefabricated boxes, but each time they actively participate in the production of a mathematics lesson in its concrete detail. The lesson itself and the natural language used - by teachers and students alike, always for the other's benefit - "permits speakers and auditors to hear, and in other ways to witness, the objective production and objective display of commonsense knowledge, and of practical circumstances, practical actions" (Garfinkel and Sacks 1986, p. 163).

In the present study, our focus is on the first classifications of three-dimensional objects and the separation of those that belong within and those that do not belong within a geometrical category system. The "particular staff" of this everyday school setting so concert "their activities as to exhibit topics of order* as their activities' achieved phenomena of order* in and as real world settings, in real time, and therein as the most ordinary achieved organizational things in the world" (Garfinkel 1996, p. 11). Here, the phenomena of order* are the particular sets of objects to be collected under the same category name; the category name is integral part of the topic of order. At the end, therefore, the cube is a thing (phenomenon) achieved, but 
this achievement exists in and as the work of the unfolding relation that characterizes this classroom. Returning to the introductory quotation, therefore, the properties of a cube and the cube itself constitute phenomena of order that exist in and as social relations; and these will, at some later point, be attributable to the individual child when it, after being asked to provide an answer to the question "What makes a cube a cube?", provides some geometrically satisfactory definition or, alternatively, goes about the classroom and collects a set of objects, all of which are consistent with the idea of a cube.

Because of the time point in these children's development, which precedes what traditional theories suggest to be the point of readiness to learn about the classification of three-dimensional objects according to geometrical properties, we are enabled to see the emergence of classical geometry in the lives of these children. Because of the way in which the teachers planned the curriculum, we anticipated there to be a social/material relation; and we anticipated the cube as cube to come to exist in and as a relation. Thus, in the end of an extended interaction that realizes these relations, the only cubes will have been placed on the mat and all the noncubes will have been removed. The teacher has some anticipation about what ought to happen, but for the students, the relevance of what is being done only exists in and as of the finalized grouping. That this is what was to be achieved can emerge for them only in and through the task, but it is an anticipated outcome - stated or not for the teacher.

Relations are social facts, that is, they are ordered things, and we name them as such: beginnings and endings, group work, and circle time in mathematics lessons are things (phenomena) that we recognize and can point to precisely because of their thing-like nature. The thing-like nature of social facts, as an aphoristic first rule of method states, is sociology's primary phenomenon (Durkheim 1919). Because they are social in nature, these things cannot be reduced to individuals, though they 
partake in the relations. These things are social phenomena sui generis, that is, of their own kind. Thus, any individual actor's point of view on the relation can only be an artifact of this very relation (Rawls, in Garfinkel 2002). In the ethnomethodological respecification of Durkheim's aphorism, and consistent with Vygotsky's take on the origin of higher psychological functions, we are interested in studying the social/material relations in which mathematics first appears for children. In the episode presented and explicated below, we observe a social/material relation in its unfolding leading to two groups of things: the ones that remain on the purple mat are consistent with the geometrical cube, the others, located off the map, are not. It is precisely this relation, itself an achievement to which the children are integral in its production and unfolding, that the answer to the question "what makes a cube a cube" first comes to exist and shape those participating in it.

Children are not the only ones learning in the course of mathematics lessons. Teachers, too, are shaped by the relations from which mathematics lessons emerge - a fact that we observe in their growing competencies to teach a particular topic in the course of teaching it on a number of occasions. For teachers, too, the higher psychological functions, their "teaching skills," exist in and emerge from the relations that they entertain with the children in their classrooms (e.g., Roth and Radford 2010).

We situate this study within an ethnomethodological orientation, which is offering a very different take on ongoing issues. This different take - requiring a different language that problematizes the all-too-easy formulations frequently used to describe and account for mathematical learning - arises from existing mathematics education and research on mathematical practices (e.g., Greiffenhagen and Sharrock 2008; Livingston 1986), though there are still relatively few studies relative to mathematical knowing and learning taking advantage of this approach 
(Greiffenhagen 2008). The focus of our take is on the concrete nature of cultural practices, which, even in mathematics, only exist in their concreteness of actually doing it and producing mathematical objects (Greiffenhagen and Sharrock 2006). This approach therefore is cognate to the orientation Vygotsky takes in articulating a concrete human psychology generally and to the juncture between individual and culture in the production and transformation of mind specifically. We therefore find it a useful approach (e.g., Roth and Thom 2009b) because it forces us to bracket (i.e., problematize, suspend, or exclude) many of the preconceptions that reign in our disciplinary field.

In this paper, we draw on this approach to present, using a substantive kind of event from the domain of mathematics education, how the local participants who staff the phenomenon, organize it from within such that at the end, the kinds of objects and relations of interest to mathematics educators, are the collective achievements of the local cohort. We write "staff the phenomenon" because the phenomenon is observable elsewhere as well, involving different students and teachers. In other words, the phenomenon of social order we describe is independent of the particular staff. What is particular about ethnomethodological studies is that they show,

in material contents just and only in any actual case, that and just how vulgarly competent members concert their activities to produce and display, to demonstrate, to make observably the case, locally, naturally accountable phenomena of logic and order, of cause, classification, temporality, coherence, consistency, and analysis, of details, of details in structures, of meaning, mistakes, errors, accidents, coincidence, facticity, reason, truth, and methods in and as of the unremarkably embodiedly ordered details of their ordinary lives together. (Garfinkel 1996, p. 11)

The ethnomethodological approach seeks to describe locally produced order by 
using the language of the "territory" rather than in concepts that constitute forms of "ineffable seeing of something" (p. 11). That is, our take eschews any of the prevalent sociological or psychological concepts mathematics education research uses unless these are part of the researchers' phenomenal field itself (Bourdieu 1992); this approach has been referred to as bracketing and is used in a number of fields to eliminate the intrusion of preconceptions into the work of a social scientist (Garfinkel 1967; Husserl 1976). What is to be achieved are "careful* description exposition[s that] make instructably observable work's uniquely coherent definiteness of details; their clarity, consistency, coherence, and the rest of the work's observable properties of logic, meaning, reason, and method" (Garfinkel 1996, p. 18-19). Here again, "instructably observable" means that the work producing social order can be seen from within the productive process and is taught as part of bringing the social order to life. For example, as part of mathematics lessons, children learn to take turns, and, in and with the admonition that they are out of order, children also are taught to recognize which forms of behavior are "out of turn."

\section{Methods}

\section{Ethnographic context}

The exemplifying materials in this paper have been extracted from a database established in the course of a 3-week second-grade mathematics curriculum on three-dimensional geometrical objects that a teacher and a mathematics education professor designed and taught together. The tasks asked children to engage with three-dimensional geometrical objects at a level that traditional psychological theories - those of Piaget and van Hiele - suggest are beyond the capabilities of 6-7year-old children (e.g., recognition and description of geometrical properties) (e.g., Roth and Thom 2009a). 
The entire unit was videotaped using two cameras. In whole-class discussions, such as the one from which the present materials were excerpted, one camera included the teacher, whereas the other one focused on the children whose turn it currently was, often sitting opposite to the teachers in the circle. The task during the previous, unit-opening lesson was to group mystery objects pulled from a black plastic bag into a developing classificatory scheme. For this lesson, the teachers had prepared a plastic bag with one object per 2-3-student group. After pulling a "block" from the bag, the children were asked to go on a "hunt" to collect other items in the classroom that "are the same as that block." Once the children had completed hunting for objects, the teacher asked them to sit in their groups arranged in a circle. Before the fragment is defined and begun through the initiating move in turn 01 , Mrs. Turner (the professor of mathematics education) and the teaching assistant have already read all the geometry words of this and the previous lesson and after Mrs. Turner has asked each group to name its collection of objects.

\section{Analytic policies}

Because we are interested in relations as social phenomena sui generis, our unit of analysis has to reflect this. Thus, a conversation is not made up of individual contributions that are put together or made to react as atoms or chemical elements that are made to combine into molecules or chemical compounds. Mixing oxygen and hydrogen does not lead us to the properties of water; nor does decomposing water molecules into oxygen and hydrogen (Vygotskij 2005). Rather, as soon as we are interested in social phenomena sui generis, the unit of analysis has to be inherently and irreducibly social, that is, it will inherently cut across and integrate different subjectivities to which it cannot be reduced. We need to do the equivalent of studying water molecules. Any individual perspective - the chemist's equivalent would be studying hydrogen and oxygen, or studying atoms - is an artifact of the 
social relation, for the intelligibility of behavior presupposes the shared nature of practices that individuals produce. Phenomena such as the Mexican waves created in sports stadiums or queuing cannot be reduced to and understood from the perspective of individual intentions, even though the collective action inherently concretizes itself in individual action (Collins 2004). But the reason or intention for the phenomenon is in excess of any individual intention or combination thereof. In talking, the turn pair is precisely one such minimal unit. To understand turn 06 in the following fragment from within the conversation as an unfolding phenomenon, we cannot say what it does until we find out the effect it has had. That is, we can only determine the nature of a locution after knowing what it has effectuated; and relative to the relation, this is available only in the subsequent turn. Take the part of turn 06 marked by "I>," which is an invitation to complete a phrase that is by design unfinished. (Transcription conventions may be found in the appendix.)

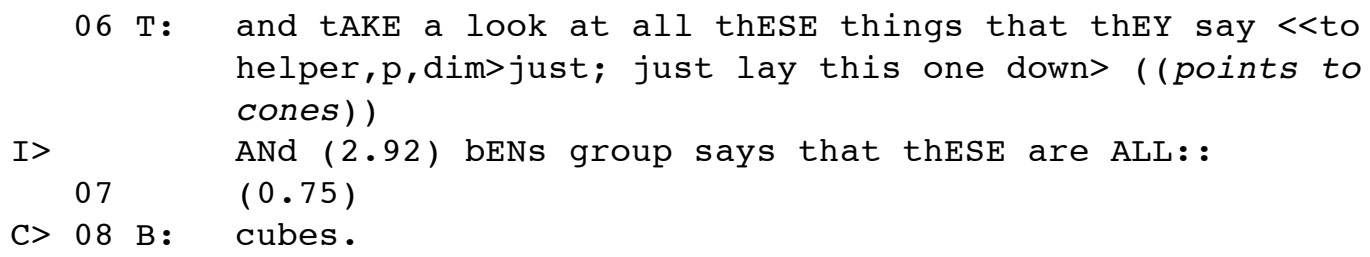

We can hear in the grammatically unfinished turn as a "designedly incomplete utterance, a pedagogical device for eliciting knowledge displays in error correction sequences (Koshik 2002). Turn 08 then constitutes the completion ("C>"). In other words, we can hear the locution at the end of turn 06 as an invitation to fill in the open slot of the name for the collection of objects on the purple mat at the feet of Ben, Ethan, and Oshin; it is an invitation in the context of turn 08 being an acceptance and accomplishment simultaneously. But the completion and accomplishment is such only because of the preceding invitation to complete. It is out of the turn pair as a whole that its parts come to be defined. In other instances, these pairs may constitute question/answer, invitation/rejection, or 
affirmation/problematizing sequences. In each case, it is only from the whole, the pair of turns actually accomplished, that we can assert the nature of a specific turn.

\section{“They say they are all cubes; so they are gonna explain to us what makes a cube a cube"}

In this section, we present and explicate one participant-defined episode from a second-grade classroom studying three-dimensional geometry. The particular episode focuses on cubes. However, we could have selected other episodes from the same day to exhibit precisely the same phenomenon. The chosen episode has the advantage that we have a more detailed record concerning relations involving cubes than involving other geometrical objects, concepts, classifications, and so on. This is not the first and not the last of the relations recorded in this classroom where cubes and their properties are integral part. It is in the development of these relations over longer periods of time that we were able to observe what mathematics educators pick out and name "cognitive growth" and "mathematical learning," or which are determined in and are reductions from other forms of relations, such as interviews or tests (e.g., Roth 2011).

Mrs. Turner says, “'They' are gonna explain to us what makes a cube a cube'. In the end, the three students all will have had their turns and those things in their collection that fit with the geometrical idea of a cube can be found on the purple mat, whereas all the other things that also had been on the purple mat have been removed. The work of this removal is collective: the children do the removal, but not because they may have intended it; and Mrs. Turner contributes to getting these things placed to the side without causally determining what is happening and how it is happening. That is, the classification of objects into cubes and non-cubes is a social relation here (first); toward the end of the unit, the children complete such classifications on their own. 
Following the production of what has been said before - here, the ensemble of reporting and reported speech is itself the result of collective work, attributing different roles to those staffing this event. In the end (turn 10), Mrs. Turner will have articulated the reporting context, whereas Ben will have said what he already has said before. (Transcription conventions may be found in the appendix.)

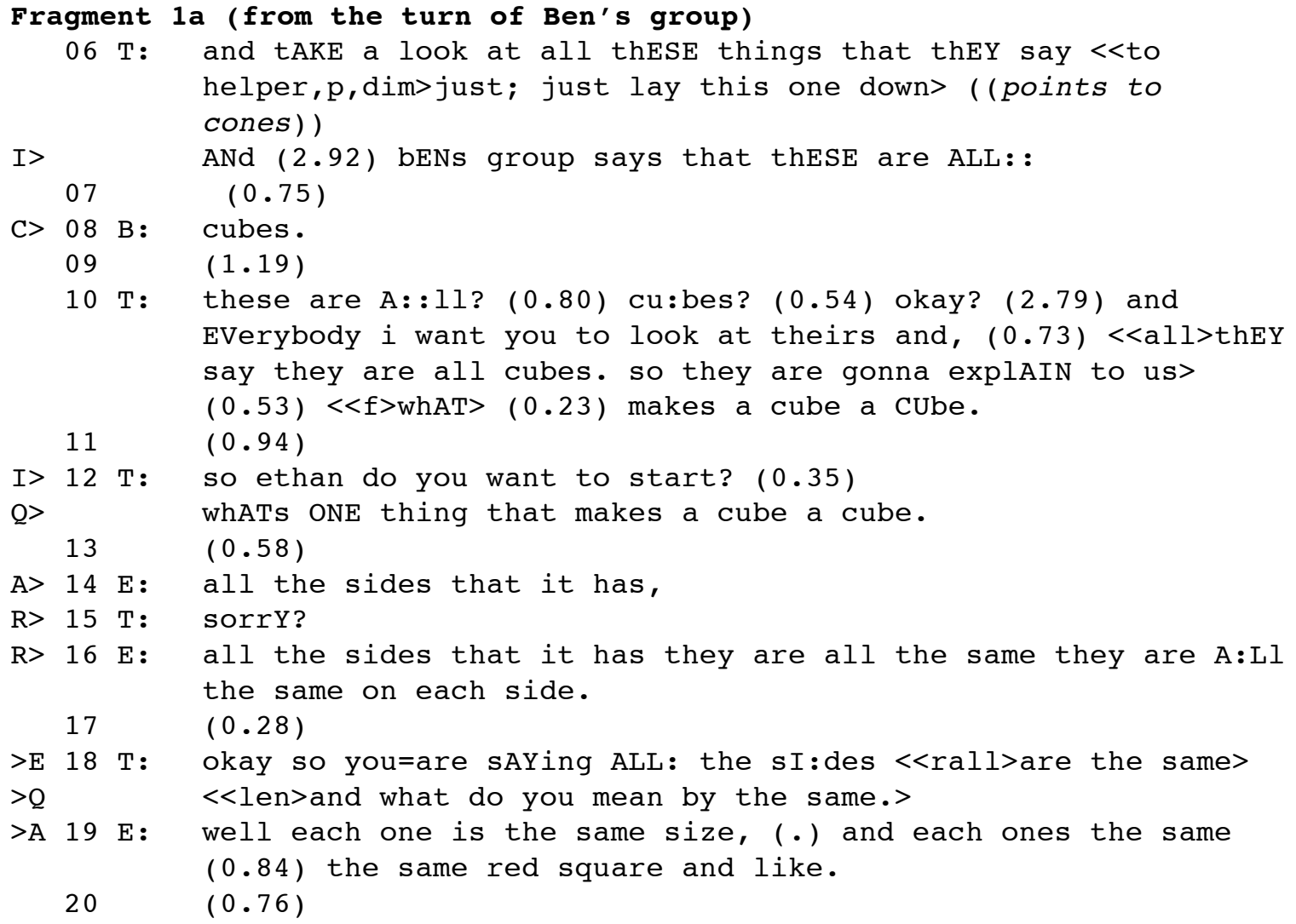

By turn 19, a statement about what makes a cube a cube has unfolded in the conversation, with aspects of the collective work distributed across speakers taking turns: "The sides that it has they are all the same; they are all the same on each side." In many classrooms, this might have already been sufficient for the lesson to go on. But here, there will have been two unresolved issues. First, not all three of the students in the group have had a turn (only Ethan has), and on the purple mat there are still things that will not have been consistent with what has been articulated - in verbal and gestural form - about the properties of a cube. 
First Oshin, then Ben and Ethan together get turns at picking out things that share properties with cubes without actually being cubes. The work of picking out things (some picked up by the teacher, others by students) and articulating likeness and dissimilarity with cubes is spread across those who staff this ordered and orderly social event.

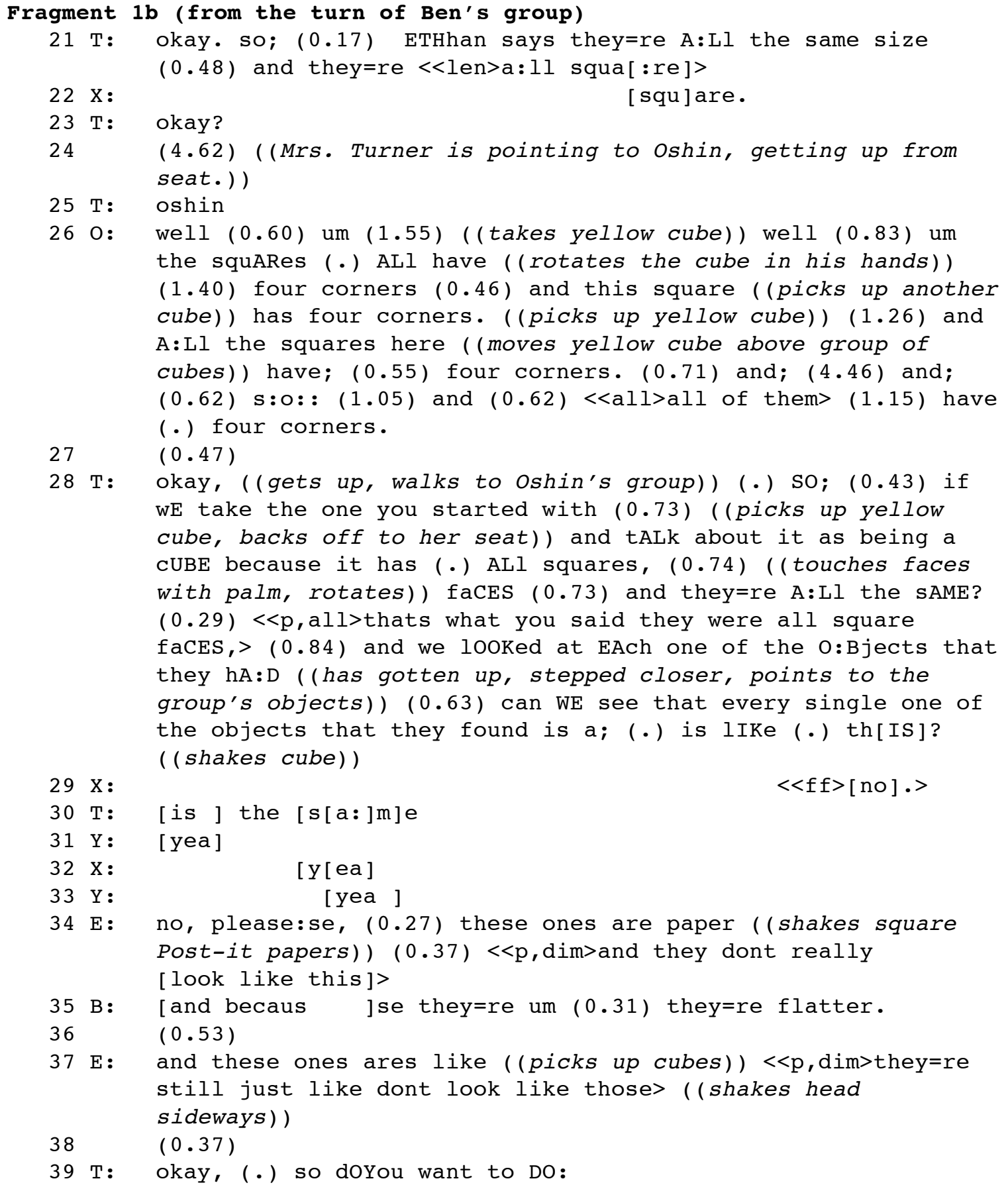




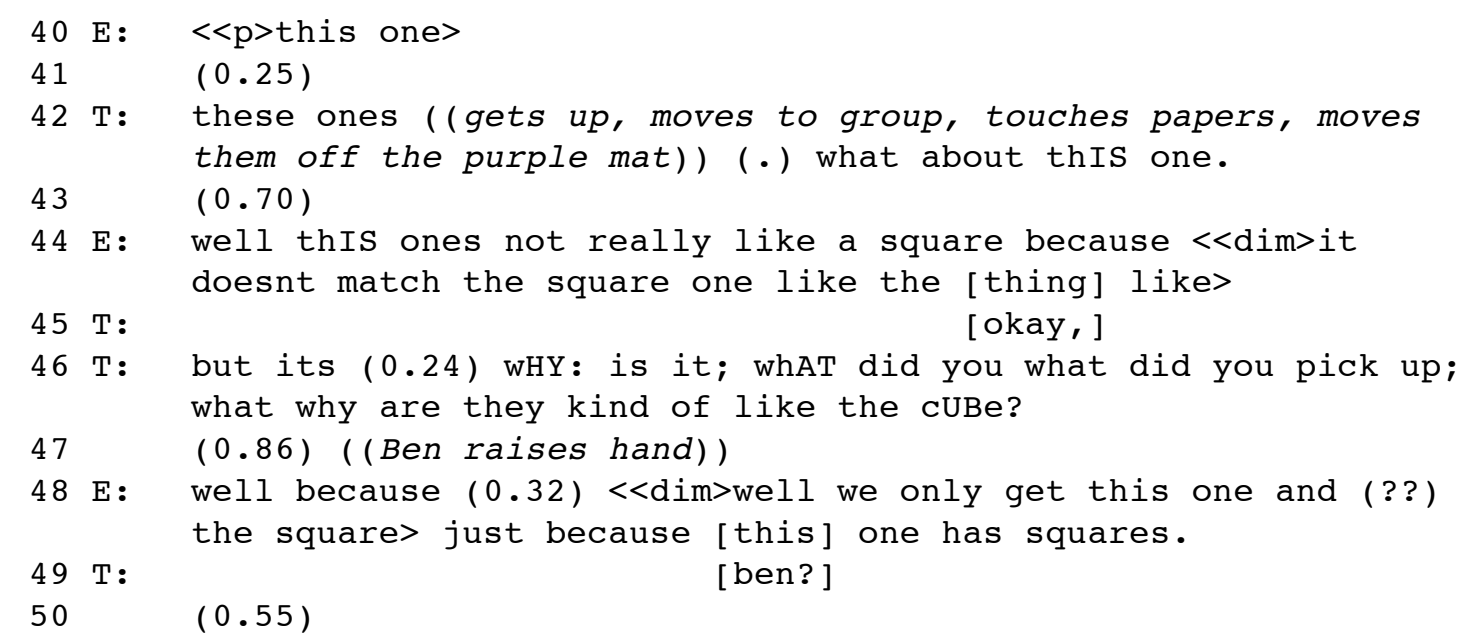

By now, all three students have had their turn. But the conversation continues to unfold when a description is produced that both states in which way a Post-it pad is similar as well as dissimilar from a cube and what is required to turn it into a cube. In gesturing from the pad up to the height of the cube next to it together with the description "if it was a little bit longer" exhibits its difference to a cube, both in terms of the property and in terms of an action that would turn it into a cube (turn 51). In the subsequent turn, what Ben has said comes to be reported back to the whole group in indirect form: "It would need to change a little bit to be a cube ... is that what you are saying?" In the more common ordering of elements in the turn, the parts of the sentence would be reversed, clearly establishing the grammatical structure of indirect speech: "You are saying that it would need to change a little bit to be a cube." But in the present context, uncertainty about the reported context is also evident in the terminally rising intonation of the locution, which both offers a version of the reported speech and invites a confirmation. Here, the preceding speaker provides the confirmation: "Yea," but also appears to begin introducing a modification with the production of a contrastive conjunction "but" (turn 54), which the next locution cuts short in inviting the removal of the current thing being talked about (turn 55).

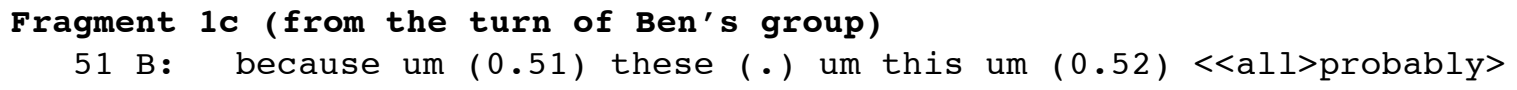


if they had more ((holds post-it stack next to cube)) um little paper (.) it would actually fill up to thERE ((filling movement from top of stack to top of cube)) (0.21) and if it was a little bit longer ((hands showing paper to be size of cube) )

$52 \quad(1.27)$

$53 \mathrm{~T}$ : okay so IT would nEEd to change a little bit to be a cube then ben. is that what you are saying?

$54 \mathrm{E}$ : yea. but.

55 T: <<p>okay, > so if you could put them OFF: can you just put them to the $\operatorname{SIDE}(0.50)$ so that we know they are no:T really cube like $(0.44)$ but $(0.92)$ but $<<$ acc, dim>they [look a little bit like cubes]>

$56 \mathrm{E}:$ ((picks up paper)) <<p $>$ [this one is like a cube $>$

$57 \mathrm{~B}:$ these ones are like (0.29) thats like (.) square ((gesture palm at face of yellow Post-it pad that he has picked up)) $57 \quad(0.54)$

$58 \mathrm{~T}:$ its a cu its like a cube because it has a [square]

59 B :

$60 \mathrm{~T}:$

61 B :

to it when you [hold it] [yea ]

$62 \mathrm{~T}:$ but then you turn it thAT way and its its not very square side of the pad, then pushes pad between two hands)) (0.26) ITS like a cube because its ^what.

$63 \quad(0.71)$

64 C: because::e um it looks like a square?

$65 \mathrm{~T}: \quad<<\mathrm{p}>\mathrm{uh} \mathrm{hm}>$

$66 \quad(0.38)$

$67 \mathrm{C}: \quad[$ an:d ]

$68 \mathrm{~T}:$ [but its] not a cube because why

$69 \quad(0.98)$

$70 \mathrm{C}$ : because its not straight ((picks up red cube))

$71 \quad(1.14)$

$72 \mathrm{E}$ : ((holding up yellow cube)) like having sides

$73 \quad(0.72)$

$74 \mathrm{C}$ : like thIS: ((strikes each of $x, y, z$ faces))

75 (2.66) ((Cheyenne places palm on side of red cube.))

76 T: doesnt have all those different sides. okay. thank you.

$77 \quad(0.35)$

$78 \mathrm{C}: \quad<$ pp $>$ [doesnt have all the sides ]>

79 T: [now we=re gonna move on to the next] group. ((Points to the group next to the one that has currently presented.))

In the subsequent turn pair sequences, further items on the purple mat are identified as topics and, after collective determination that these are not cubes, placed next to the purple mat. Although there are many more items on the mat, these never become the topic, as if these were already fulfilling an unstated quality that makes them deserve their place on the map. That is, in the course of the turn 
taking, the children and teacher discuss items that are subsequently removed, whereas most that end up on the mat will have never been the topic of talk or transitive object of some action.

What the children have done, before an open horizon of possible things to do, becomes relevant only after the fact, when whatever ends up on the purple mat simultaneously constitutes the answer to the question that was part of the initial gloss of the task: "So they are going to explain to us what makes a cube a cube." This episode produces precisely that: an explanation, or, to be exact, multiple articulations of in what the cubical nature of the cube exists. This includes, for example, the fact that it can be rotated to expose each time a square (Fig. 2); and those items that are not cubes may be square in one orientation but, because these are "flat," clearly not in another orientation (Fig. 1). Here the presence or absence of the square properties, literally in the hands of the children, have come there in and through the form of social relation that we see unfolding in the lesson fragment.

The endpoint has been achieved with the "thank you," an aphetic for "I thank you," which may be heard as an acknowledgment not only to Cheyenne (other students had not been thanked before), but in fact to "Ethan's group." Mrs. Turner continues after only little pausing and while Cheyenne is also talking with very low speech volume, offering up in a constative "Now we're gonna move on to the next group" (while pointing to another group), an initiation of another group's turn.

In the course of this episode, we observe a transformation of what is claimed to be a collection of cubes into what de facto is a collection of cubes from a mathematical perspective. As the classroom talk unfolds, producing time as much as taking it, the reported speech following the "They say that ..." comes to be exhibited right here in the public arena of the circle as a statement that turns out to be untenable, in fact, the untenability of which the children themselves contribute to producing. But in the end, because now a number of things have been removed, the 
collection of Ben's group is, from the perspective of historical geometry, consistent with their statement. Rather than changing their statement, the collection of things comes to be changed so that the statement is tenable.

The orderly properties of geometry exist, in part, in and as of the orderly properties of the sequentially ordered turn-taking, whereby each child from the group (Ethan, Ben, Oshin) and one other child (Cheyenne) gets one or more turns within this sequence of turns. The orderly properties of these concrete objects, from which are to emerge the properties of the associated ideal geometrical objects, exist in and as of the details of this relation; in fact, they are premised on these orderly properties.

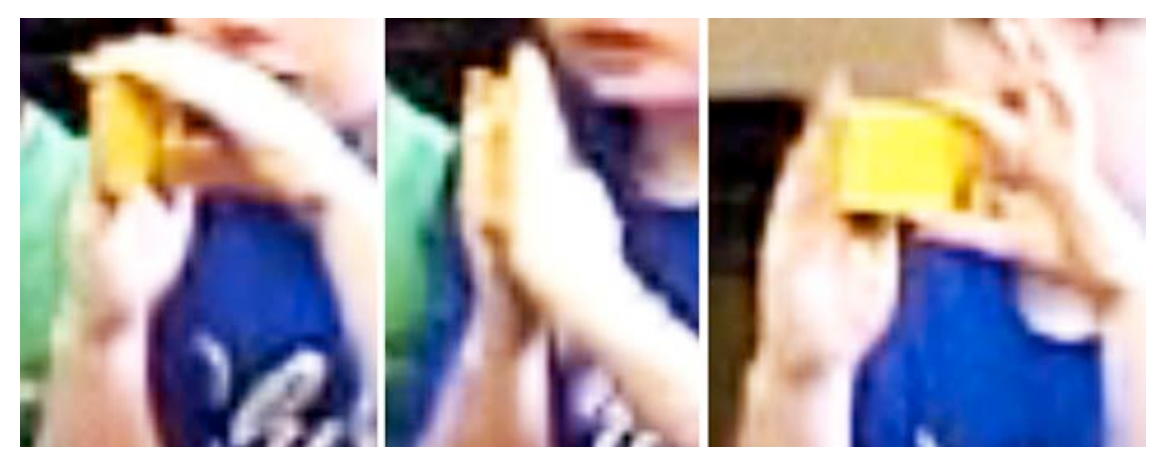

Fig. 1. Why this Post-it pad is not a cube

The geometrical "definition" is "in hand" - first literally in the way the children hold the non-cubes (e.g., Fig. 1) and the cubes (e.g., Fig. 2) and only later on the purple mat, where the teacher has asked Ethan's group to place all objects on. The collection on the purple mat is the end result of the relation that we observe in this participant-defined episode (participants themselves mark the beginning and end). In this episode, the teacher offers an invitation to Ethan and his group to talk about the objects they have collected and to answer the question "What makes a cube a cube?", and she ends the episode by moving on and identifying another group of 
students whose turn it is to name, explain, and articulate properties of the group of objects that it has collected.
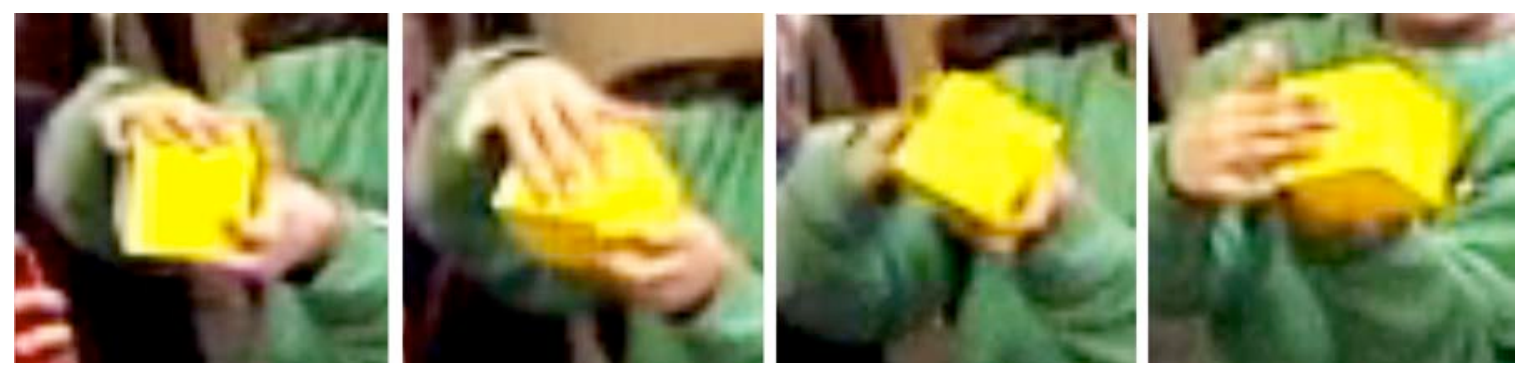

Fig. 2. Why this is a cube: "They are all the same sides."

In what precisely lies their achievement? The point is not that the three boys had done something incorrectly, that they had had a naïve conception about the classification of three-dimensional objects according to geometry that had been corrected in the course of this episode. Instead, whatever the three boys had done that led them to the collection of objects that they brought to the circle is correct within a particular "game"; what the episode demonstrates is the difference between that game and the one played in the course of the circle meeting. In fact, on the preceding day, there was one group of objects bearing the label "squares, cube." The present collection is consistent in such a game of squares and cubes. Literally, then, this episode was a "game changer," where the collectively achieved removal also brought about the change to a different kind of game, with different rules about what could be contained in the collection of objects "similar" to the one initially pulled from the plastic bag.

In what, then, did their achievement lie? Mrs. Turner articulated what after the fact can be recognized to be a prospective gloss of the event. "Take a look at all these things ... Ben's group says that these are all cubes ... so they are going to explain to us what makes a cube a cube." In the end, not only were explanations provided, but 
also all members of the group had their turn, and all things that are on the purple mat are cubes and all things that had been on the mat but have been recognized as non-cubes have been removed. This is, in so many words, a gloss of the events in the words of the participants. But how did they get from where they were, with a mat full of things not all of which were cubes to the final situation that there were only cubes on the mat. We are looking for an answer not in general, but in the concrete details of their situated work, dealing with contingencies as these arise. It is only by knowing the precise work that gets us from some Point A in a lesson to some Point $\mathrm{B}$, in any concrete case, that a research account can be of practical use, because what it describes is instructably observable. We can use it then to teach others how to get from Point A to Point B in a mathematics lesson and how to recognize that something gets us from the former to the latter point. The work remains invisible when a mat already contains objects of one kind only. In the present instance, what becomes observable - and seeing this can be taught - is precisely the kind of relation that Vygotsky is talking about as the beginning, the first occurrence of higher psychological function in the life of a child. The work of ordering, describing, adding, selecting, excluding, etc. things because they are like or unlike is precisely what the present study exhibits in phenomenal detail. This is so because the observable and observed work achieves what in other instants already has been achieved (e.g., when children classify correctly and without delay). But in those cases, an earlier instant in the development of the children would have had to be chosen to see the same original relational work in action.

The situation we present is what has been called a perspicuous setting, where practices that "have become embodiedly transparent in their familiarity" (Garfinkel 2002, p. 211), are exhibited such as to become describable and instructable. Ours is a perspicuous setting for making visible first participation in geometry-focused social/material relations that at some later point are made attributes of the 
individual mind - and this even though the participation already has to involve the mind otherwise the children could not participate at all. It is in this setting that we find the disclosure of the "local production and natural accountability in technical details with which to find, examine, elucidate, learn of, show, and teach the organizational object as an in vivo worksite" (p. 181). This is the relation that psychologists such as Piaget and van Hiele attributed to the mind as higher psychological function - finding objects that are like some reference block from a classical geometrical perspective. Here it is made visible in all its concrete detail, and where these very things are made visible by, to, and for the benefit of the members to the setting, that is, of those who staff the phenomenon.

\section{The positive function of the third position in IRE for reproducing geometry as objective science}

Researchers have identified a particular sequential organization of classroom talk, denoted by the acronym IRE, whereby teachers initiate a turn sequence, students reply, and teachers evaluate (e.g., Poole 1994); more recently, expansions of this pattern have been proposed, which deal with particular contingencies that might arise when the preceding sequence has not yet sufficiently accomplished legitimization through the evaluative turn (Gardner in press; Lee 2007). This form of turn taking has been much maligned - with respect to mathematics education see Cazden's, 2001, discussion of the work of J. Hiebert, M. Lampert, and D. Ball without general acknowledgment that it may in fact serve a definitive function in the "handing down" of the sciences such as mathematics.

The emergence of pointing as an intentional gesture is a good example of how a social relation becomes a higher psychological function (Vygotsky 1978). Initially a child may attempt to grasp an object placed a little out of its reach: "at this initial stage, pointing is represented by the child's movement, which seems to be pointing 
to an object - that and nothing more" (p. 54). In fact, we may say that there is no pointing but only movement. The situation is radically changed when the parent takes the object and tends it to the child; in this situation, the movement becomes a gesture for another person. The gesture of pointing comes about in the relation precisely when, subsequent to the first or several first attempts of such grasping movements, other interaction participants consistently tend an object to the child. The grasping movement has become a pointing gesture in and through the relation in which the movement has become treated as a gesture directed towards others. It is in and through the parent's turn that a child's movement becomes a social phenomenon. There is an evaluative turn on the part of the parent, which is central to the conversion of an arbitrary movement into intentional pointing.

The IRE turn taking sequence can be seen to have precisely the same function. However, rather than having evaluations of more-or-less random movements and sentences that are evaluated, in the for-schools-characteristic sequentially ordered turn taking, the initiation is assigned to the teacher. This can be seen, for example, in turn 12, which offers up an invitation and question, and which is actualized as such in its de facto acceptance and answer in turn 14, which expands into turn 16 (following the interrogatively intonated "sorry?" that tends to be heard as a request for repeating words that a recipient has failed to catch, or technically a repair initiation). The beginning of turn 18 takes the third slot in the sequence, whereby Mrs. Turner uses the grammatical device of indirect reported speech ("So you are saying [that]") to articulate just what the preceding turn has stated: "All the sides are the same." Although there is no direct or indirect statement about the preceding locution being correct or incorrect, two parts of the earlier locution are pulled together to constitute the reported context within the reporting context and reformulation of Ethan's turn, which is in turn 18. 


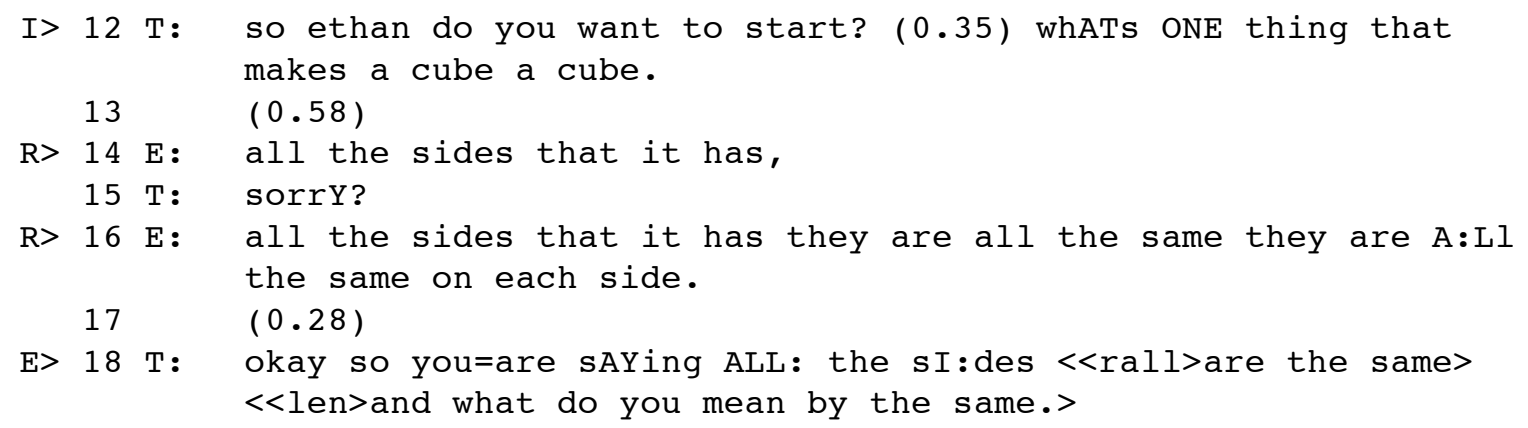

Turn 28 makes use of the same device of reported speech, "they're all the same. That's what you said, 'they were all square faces'."

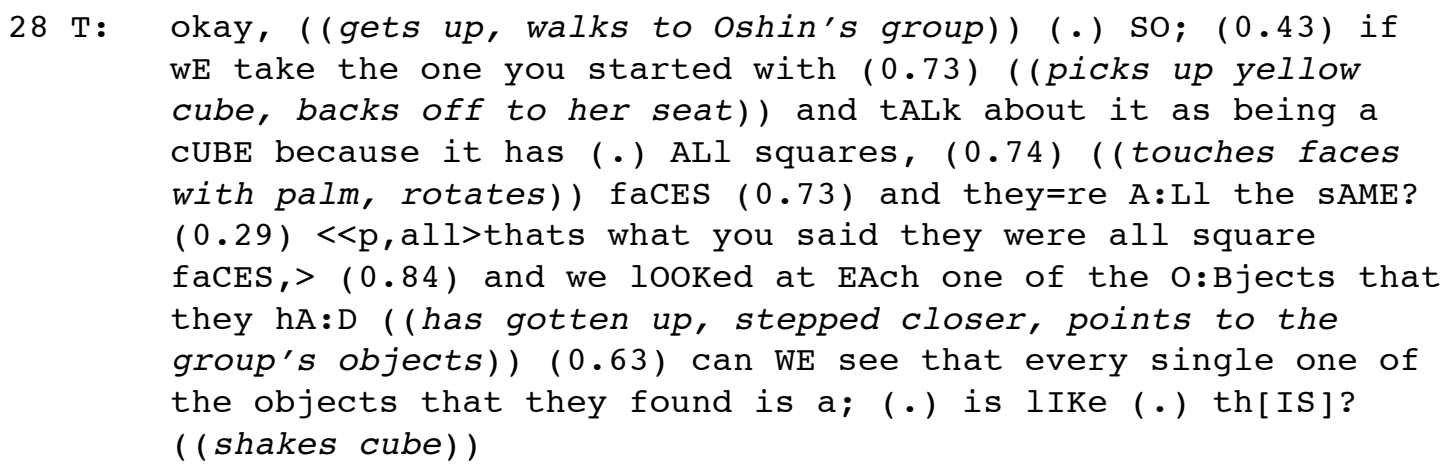

In this indirect reported speech, what the children have said is transformed, and it is precisely this transformation and its relation to the reporting context that the evaluation consists of (Vološinov 1930). It is a form of developing the theme, here the one of cubes.

In turn 28, there is another initiation. With the yellow cube in her hand, Mrs. Turner offers up an initiation, which is actualized with the completion of question/answer pairs: "Can we see that every single one of the objects that they found is like this?" There are elaborations of why some of the items are not like the yellow object that had been held up, and then the adverb marking adequacy or acceptance and readiness to move on ("okay," turns 39, 45) (cf. Gardner 2001). In turn 46 , the students' action of adding certain items that now are defined as not constituting cubes, is reported indirectly "What did you, what did you pick up, what why are they kind of like the cube?" That is, having been picked up as being like the 
yellow object (cube), the things now sorted out (sheet of square paper, block of Post-it notes) are acknowledged as having some property that makes them like a cube. This turn therefore also constitutes an initiation of a sequence that elicits articulation of that property that is alike at the same time as acknowledging that the thing as a whole is not like the reference object (turn 46).

We then observe another indirect reported speech in the third slot, following initiation (turn 46), reply (turn 51), and the indirect reporting of just what Ben has said without having said it in so many words (turn 53).

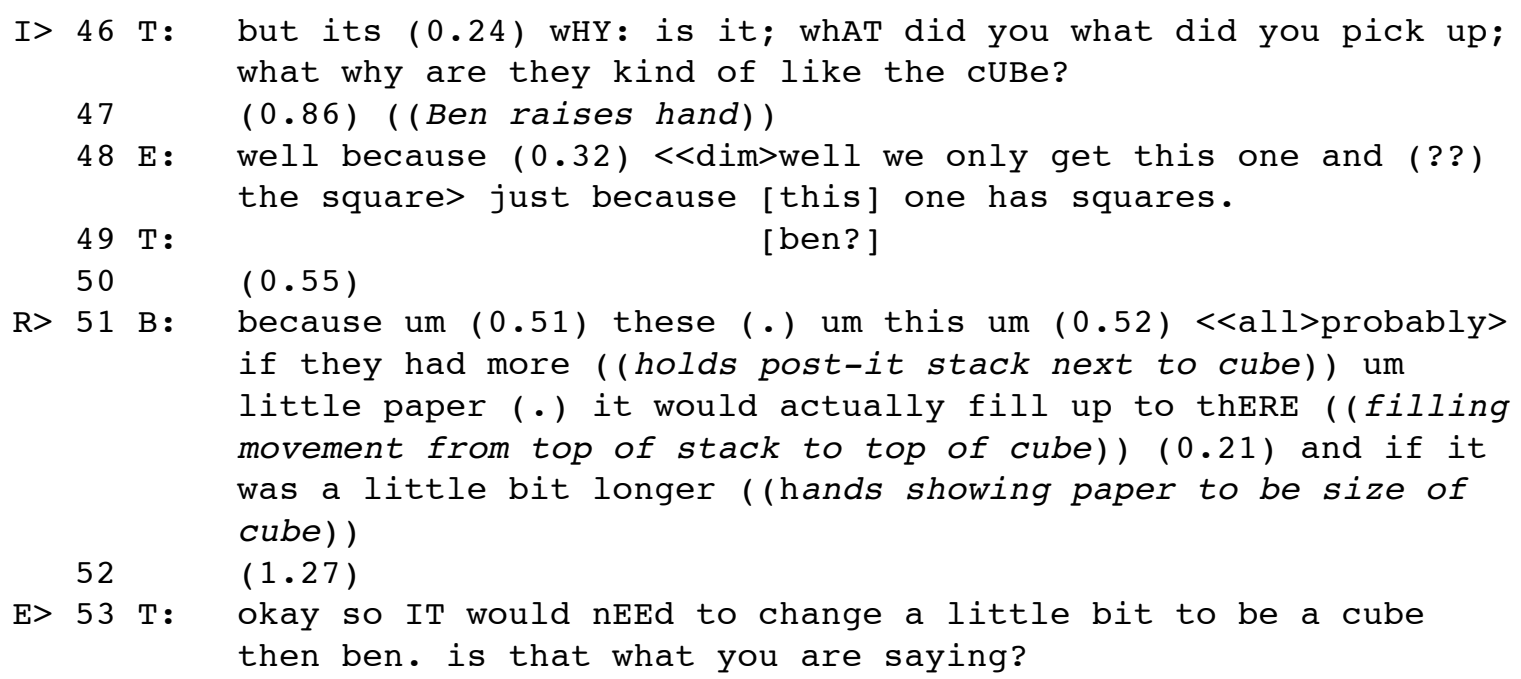

There are further turns that constitute the second and third positions in the sequence following the initial question, as can be seen in the following fragment that attributes to Ben another second position, where the third position uses indirect speech to articulate just what Ben has said relevant to the question at hand (why is it like a cube without actually being one?)

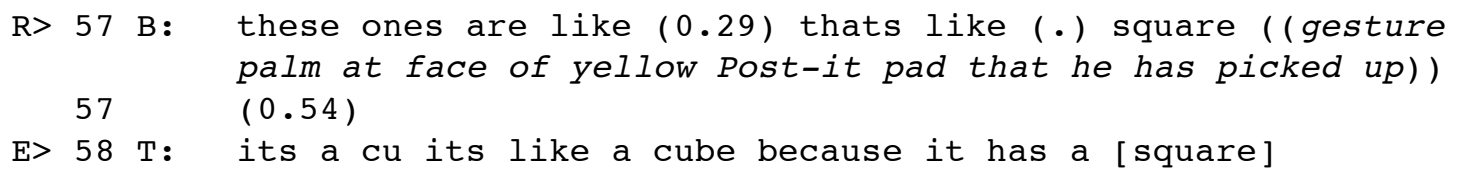

The pattern repeats itself yet another time, where turn 62 invites Cheyenne to take a next turn by naming her, and offering up a formatted question concerning "the piece of paper": "It's like a cube because it's what ...?," where the question- 
word-final locution constitutes the equivalent of a Cloze procedure.

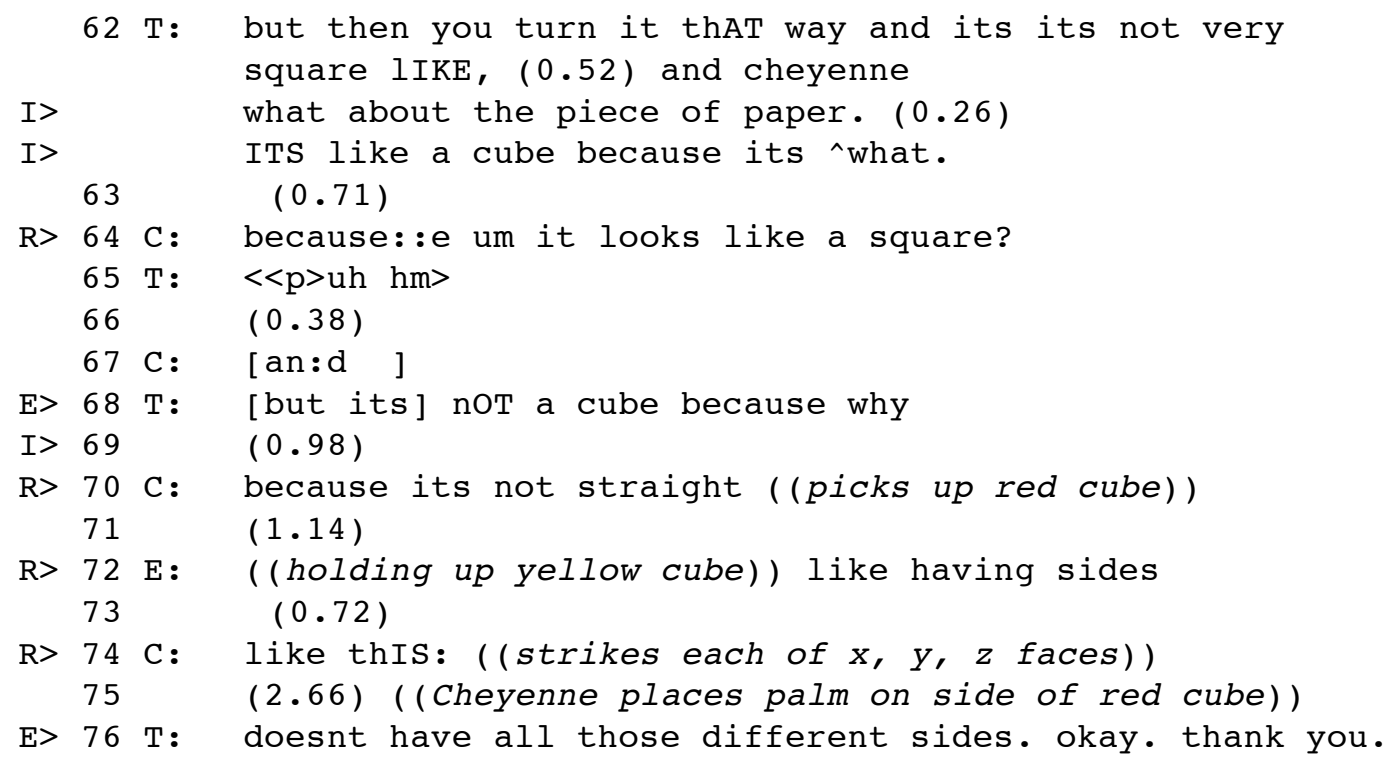

Here, turn 76 articulates just what has been accomplished in the turn pairs preceding it. Although turn 68 appears to constitute an elaboration of the initiation turn 62, it in fact also constitutes an evaluative turn. In allowing the preceding turn without explicit (negative) evaluation, it accepts it as a matter of fact so that the talk indeed may turn on to the next matter. This matter, here, concerns the dimension in which the piece of paper is not like a cube. Whereas Ethan and Cheyenne had used gestures and said "because it's not straight," "like having sides," and "like this," in the reporting context the children are suggested to have said - using indirect reported speech - that it "doesn't have all those different sides." This statement of affairs is marked as satisfactory, adequate, and acceptable ("okay"), the contributions are acknowledged ("thank you"), and the talk marked as being ready to move on to the next group - unless, of course, a next turn were to offer up an extension to what has happened so far or in some other way of leading to a different course of action than getting the next group have its turn.

In fact, even the "opening" turn offering up to Ethan's group an invitation to explain what makes a cube a cube already is a turn of this type, for it is in response 
to an instance that had occurred a few minutes earlier in the lesson when all the student groups were asked to volunteer a name for their collection of "blocks." Ethan and Ben, asked to select one of the names from a list that would fit their group, named it "cubes." In turns 06 to 08, although Ben's answer only contained one word, the reporting context constitutes what has been said in a different way: "Ben's group says that these are all cubes."

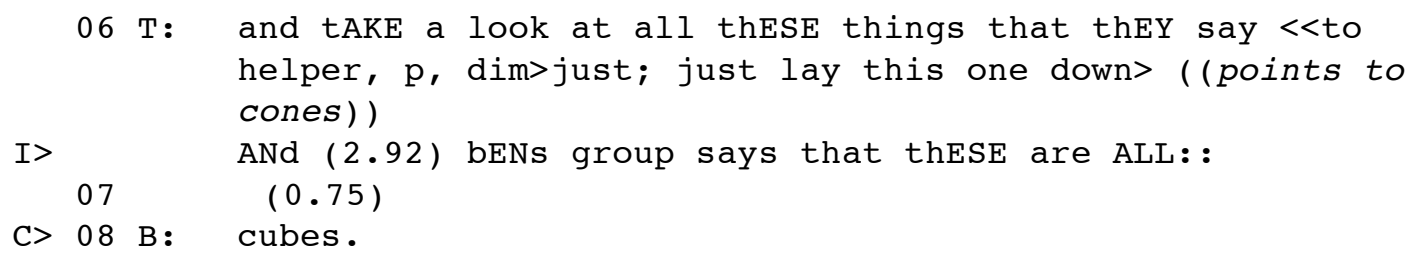

The reporting context presents the problematic, drawing in part on what the students had said, and then invites the others "to take a look at all these things" and “look at theirs," while Ben's group is invited to explain what makes a cube a cube.

It is the particular structure of the third turn - its reporting function and reformulation of the children's utterances - that locates and extracts from preceding talk what might be useful for the prospectively achieved explanation and response to the opening question, "What makes a cube a cube?" and for locating whatever other resources that justify removal of the current item from the purple mat. It is precisely after a child has produced a property that distinguished the item from the reference "block," here the yellow cube, that it is removed; the removal itself therefore comes to be grounded in the children's actions even though it is a result of the interactional work that includes the teacher. These actions thereby obtain their significance once what has been said and done figures in the context of the reporting speech.

The children are learning geometry; and for this reason, they are unlikely to be in the position of producing a third position turn for the phenomenon, which presupposes existing familiarity with the historical context in which the current 
situation is to find its place. It is precisely in this sequence of turns 62 to 76 that the orderly sequence produces the properties of the paper, which, in having some properties that make it "not a cube," eliminates it from the set on the purple mat that defines what makes a cube a cube and objects that look in some aspects like a cube but have other properties that make them unlike cubes (Fig. 3). In this relation, we observe an orderly social phenomenon that produces something very similar to what the classical concept learning experiments had done: learning a concept by coming to understand in which way one collection, "all of which are X," is distinguished from another collection, "none of which are X."

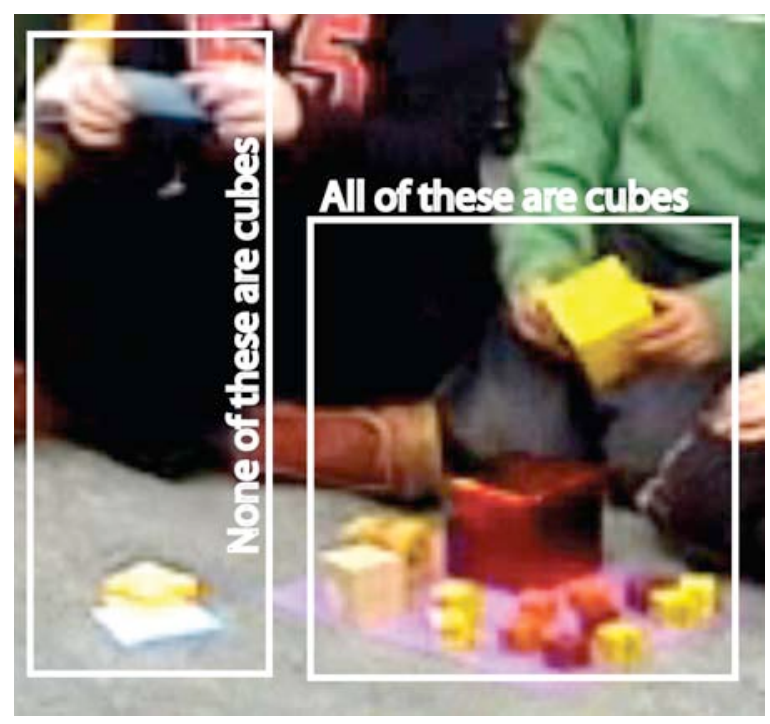

Fig. 3. The achievement: spatial and, therefore, conceptual separation of cubes from non-cubes.

Rather than something to be maligned, the three-turn structure of sequentially ordered and orderly classroom turn taking, as an integral aspect of the irreducible social phenomenon "classroom routine" that is to be taken as a fact, also has the function to "exhibit ... the population that staffs it" (Garfinkel 1996, p. 5) and, with it, the functions associated with the particular participants. Students are students 
because of the particular places they take within the turn taking, just as teachers are identified by the positions that they take in turn taking rituals. From the perspective of irreducibly social phenomena, the IRE sequence transcends the teacher's intentions; the sequence is a social phenomenon staffed in this case by Mrs. Turner. It is staffed differently in other situations, such as in the driver's license bureau or in our university's annual fire-training certification, where the computer initiates, the want-to-be-licensed individual responds, and the computer evaluates; and it is staffed again differently in the hiring process, where the hiring committee initiates and evaluates the responses of the applicant currently being interviewed. But, in all these different situations, the orderly structure of the routine remains the same. The IRE sequence, therefore, has an important societal function. The sequence reproduces what past generations have built up as cultural knowledge that serves society in meeting generalized, basic and extended needs.

\section{Society is in the mathematical mind because the mathematical mind is in}

\section{society}

One of the core debates in mathematics education concerns the nature of the field, which for some is an objective science whereas it is for others merely a social construct. In an insufficiently attended to analysis that should be of interest to all mathematics educators, Husserl (1939) articulates, using geometry as an example, science as being objective even though it is fundamentally realized in every single case by the singular actions of concrete individuals. Thus, some sense formation originally emerges spontaneously - in the way Vygotsky's child spontaneously produces a movement; remembering such an initial production in the future constitutes an active, real production. In this reproduction of what is remembered, there is also recognition of and evidence for the identity of the remembering act and what is being remembered. The original production of sense therefore also creates 
the possibility of an unlimited repetition of the original sense-attributing event, the identity of which is given in the repetition of the material praxis and objects therein. That is, geometry as objective science is reproduced precisely at the point where there is evidence for the identity of praxis and the role of the material forms in the chain of reproduction.

In the present episode, geometry is reproduced as objective science in and as of the relations we observe; and it is precisely because it exists in these relations that geometry is reproduced and will be reproduced in a continual chain of a tradition that makes for the history of geometry. It is precisely because the mathematical mind is in society, to paraphrase the title of Vygotsky's (1978) book, that society is in the mathematical mind. This approach overcomes (sublates) any dichotomous theory that contrasts inside (intra-psychological) and outside (inter-psychological) because any phenomenon that might interest us not only involves the back-andforth movements across some boundary between an inside and an outside but also, and in fact, defines this boundary in the first place. From the cultural-historical perspective, any consciousness is the inner reflection of concrete praxis (Leont'ev 1983; Lerman 2000), which corresponds to ethnomethodological position that the actor's point of view is but an artifact of social relations (Rawls, in Garfinkel 2002). In other words, the language on which the relation is built "is not the reflection of subjective-psychological hesitations but of the stable social relations of the interlocutors" (Vološinov 1930, p. 116, our translation) that are themselves, reflexively, the product of the relational work.

The episode presented here also produces a phenomenon that is a common feature of society, but especially developed in the formal sciences: the production of accounts. Thus, in any "organized arrangement," participants are engaged in and requested to "decide, recognize, persuade, or make evident the rational, i.e., the coherent, or consistent, or chosen, or planful, or effective, or methodical, or 
knowledgeable character" (Garfinkel 1967, p. 32) of whatever they participate in, including their classifications and descriptions of properties (squares, all are the same). It is precisely because such accounting occurs in public arenas that participating in the social/material relations integral to and constitutive of these events allows children to become increasingly knowledgeable. As a result, years later in an individual exam situation, they will be able to knowledgeably justify their responses to an item.

The sequentially ordered triadic turn taking IRE sequence has a precise role in this production of geometry, which, to be a link in the history of geometry, needs to be recognizably identical with previous instantiations of praxis and objects found therein. This is, we suggest, where in particular the third position in the routine has a place, because it is in it that the past comes to bear on the present. It identifies those instances that are consistent with the preceding chain of repetition of the original geometrical experiences (during the times of the Greek) and the current instantiations, which, like Vygotsky's spontaneous movement and Husserl's spontaneous act of idea generation, do not have inherent signification. It is in and through the third-turn position that the current act comes to be marked or evaluated as a repetition and separated from those acts that are not repetitions of the original idea. It is because of this third position that children can learn to distinguish those instances in their subjective productions that are consistent with geometry as objective science and those that are not. What the turn-taking sequence achieves, with the third-turn use of reported speech, is yet another structure at the inside of the structure, as "what manifests itself in the forms employed for reporting speech is an active relation of one locution to another" (Vološinov 1930, p. 114, our translation); and, importantly, this phenomenon of order is not at the level of the current theme "but by the means of the relevant, stabilized constructional pattern of the language itself" (p. 114). Moreover, the indirect reported speech in the third 
turn, which partially conserves "the syntactic, stylistic, and compositional unity/ uniqueness" (p. 117) of the original, retains and thereby gives value to the children's voices.

Both framings, Husserl's and Vygotsky's analysis of the production of intentional acts, require an evaluation of identity of a current act with a previously accomplished one, and those of present objects (language) with those that have been traditionally associated with the acts in the past. Just as Vygotsky's infant finds the social significance of its movement in the acts of the parent, turning them into intentional pointing movements, the children in this mathematics classrooms are provided with an opportunity to find the social significance of their acts in the contents of the third-turn part of the IRE phenomenon. Indirect speech allows the teacher to retain what the student has said, directly referring what she is saying to the preceding speaker, but also - by placing it in an evaluative reporting context - to transform what a child has said in the service of situating it in and distinguishing it from the historical context.

Whereas reported speech has as its important function the production of a historical tie, whereby what is reported is transformed and reproduced into a new context, the function of reporting speech in the present instance is different. Here it is the reporting context that is (more or less) consistent with the tradition and the function of the reporting speech is to situate what children have said in this historical context, at times requiring a modification. Such modification is possible in the use of indirect speech, which shapes what has been said by assimilating the speech of another to fit the intentions of the narrator (Vološinov 1930), whereas direct speech takes on precisely what the preceding speaker has said. It is this turn that constitutes both a backward tie to the already existing history of geometry and a forward tie to the projected achievement of a proper geometrical classification in the here-and-now of the present setting. 


\section{Methodical coda}

A final word is required concerning the possible limitations of a single case study. Some scholars are concerned when research papers present only one detailed case study to exhibit a particular phenomenon. The fact that there might only be one student or student group involved raises concerns. However, in this paper, we are presenting a particular phenomenon, the function of the third-term in the sequentially organized turn taking. The particular case chosen is that of the production of geometrical properties and classifications in social/material relation. It is this phenomenon itself, or, rather, "it is the workings of the phenomenon that exhibit among its other details the population that staffs it" (Garfinkel 1996, p. 5). Generalities about such relations neither capture the phenomenon nor can these lead to an integration across settings because the concrete phenomenon is lost with the particulars; it is precisely in the particular details of every such case that the general can be found (Durkheim 1893). This is so because "[i]t is impossible to found the concrete character and distinctive properties of the things at the heart of the same impersonal and homogeneous formula" (p. 407, our translation).

In this paper, instead of taking the classical approach to qualitative research, we take an ethnomethodological stance. In this, our episode constitutes a concrete document of a phenomenon that we only know through the different ways in which it documents itself: Such "orientation to the documentary, the grasping of the homology in the most diverse sense contexts, is something particular that must neither be confused with addition or synthesis nor with abstraction of common characteristics" (Mannheim 2004, p. 127, our translation). Thus, the challenge we meet in the present paper is "to systematically interrogate the particular case by constituting it as a 'particular instance of the possible"' (Bourdieu 1992, p. 233). In this paper, those who staff the phenomenon of interest, in this case, includes Ethan, 
Ben, Oshin, Cheyenne, and Mrs. Turner in one specific mathematics classroom. Had we focused on another situation - learning to take the test in a driver's licensing bureau or learning a language - we would have found the same relations staffed differently. Thus, from the perspective taken, it is not the role of student or teacher that explains phenomena of participation, knowing, or learning, but the phenomenon that exhibits details of the population that staffs this particular kind of phenomenon. That is, our concrete example exhibits mathematics education as it actually happens, but the phenomenon it represents, including many of its details, can be found in other parts of society. It is precisely that our case is general all the while remaining concrete in its tiniest detail.

\section{Acknowledgments}

The data collection was supported by a grant from the Social Sciences and Humanities Research Council of Canada. The authors thank the children and teachers for their participation. We also thank the members of the Transcription Analysis Group (TAG) - which brings together scholars from the University of Queensland, Queensland University of Technology, and Griffith University for the purpose of interactively analyzing data - for their comments on the data and to our developing ideas.

\section{References}

Bourdieu, P. (1992). The practice of reflexive sociology (The Paris workshop). In P.

Bourdieu \& L. J. D. Wacquant, An invitation to reflexive sociology (pp. 216-260). Chicago, IL: University of Chicago Press.

Cazden, C. B. (2001). Classroom discourse. Portsmouth, NH: Heineman.

Collins, R. (2004). Interaction ritual chains. Princeton, NJ: Princeton University Press. 
Durkheim, E. (1893). De la division du travail. Livres II et III [On the division of labor. Books 2 and 3]. Paris, France: Felix Alcan.

Durkheim, E. (1919). Les règles de la méthode sociologique septième édition [Rules of sociological method 7th ed.]. Paris, France: Felix Alcan.

Gardner, R. (2001). When listeners talk. Amsterdam, The Netherlands: John Benjamins.

Gardner, R. (in press). Conversation analysis in the classroom. In T. Stivers \& J. Sidnell (Eds.), The handbook of conversation analysis. Oxford, UK: WileyBlackwell.

Garfinkel, H. (1967). Studies in ethnomethodology. Englewood Cliffs, NJ: PrenticeHall.

Garfinkel, H. (1996). Ethnomethodology's program. Social Psychology Quarterly, 59, $5-21$.

Garfinkel, H. (2002). Ethnomethodology's program: Working out Durkheim's aphorism. Lanham, NY: Rowman \& Littlefield.

Garfinkel, H., \& Sacks, H. (1986). On formal structures of practical action. In H. Garfinkel (Ed.), Ethnomethodological studies of work (pp. 160-193). London, UK: Routledge \& Kegan Paul.

Greiffenhagen, C. (2008). Video analysis of mathematical practice? Different attempts to open up mathematics for sociological investigation. FQS: Forum Qualitative Sozialforschung / Forum Qualitative Social Research, 9(3). Accessed April 1, 2012 at http://nbn-resolving.de/urn:nbn:de:0114-fqs0803323.

Greiffenhagen, C., \& Sharrock, W. (2006). Mathematical relativism: logic, grammar, and arithmetic in cultural comparison. Journal for the Theory of Social Behaviour, $36,97-117$.

Greiffenhagen, C., \& Sharrock, W. (2008). School mathematics and its everyday other? Revisiting Lave’s “Cognition in Practice.” Educational Studies in 
Mathematics, 69, 1-21.

Husserl, E. (1939). Die Frage nach dem Ursprung der Geometrie als intentionalhistorisches Problem [The question of the origin of geometry as intentionalhistorical problem]. Revue Internationale de Philosophie, 1, 203-225.

Husserl, E. (1976). Husserliana Band III/1. Ideen zu einer reinen Phänomenologie und phänomenologischen Philosophie: Erstes Buch: Allgemeine Einführung in die reine Phänomenologie [Husserliana vol. III/1. Ideas to a pure phenomenology and phenomenological philosophy vol 1. General introduction to a pure phenomenology]. The Hague, The Netherlands: Martinus Nijhoff.

Koshik, I. (2002). Designedly incomplete utterances: A pedagogical practice for eliciting knowledge displays in error correction sequences. Research on Language and Social Interaction, 35, 277-309.

Lee, Y.-A. (2007). Third turn position in teacher talk: Contingency and the work of teaching. Journal of Pragmatics, 39, 180-206.

Leont'ev, A. N. (1983). Dejatel'nost'. Soznanie. Ličnost'. [Activity, consciousness, personality]. In Izbrannye psixhologičeskie proizvedenija vol. 2 (pp. 94-231). Moscow, Russia: Pedagogika.

Lerman, S. (1998). Research on socio-cultural perspectives of mathematics teaching and learning. In A. Sierpinska \& J. Kilpatrick (Eds.), Mathematics education as a research domain: A search for identity. An ICMI study book 2 (pp. 333-350).

Dordrecht, The Netherlands: Kluwer Academic Publishers.

Lerman, S. (2000). The social turn in mathematics education research. In J. Boaler (Ed.), Multiple perspectives on mathematics teaching and learning (pp. 19-44). Westport, CT: Ablex.

Livingston, E. (1986). The ethnomethodological foundation of mathematics. London, UK: Routledge \& Kegan Paul.

Mannheim, K. (2004). Beiträge zur Theorie der Weltanschauungs-Interpretation 
[Contributions to the theory of worldview interpretation]. In J. Strübing \& B. Schnettler (Eds.), Methodologie interpretativer Sozialforschung: Klassische Grundlagentexte (pp. 103-153). Konstanz, Germany: UVK.

Poole, D. (1994). Routine testing practices and the linguistic construction of knowledge. Cognition and Instruction, 12, 125-150.

Roth, W.-M. (2011). Geometry as objective science in elementary classrooms: Mathematics in the flesh. New York, NY: Routledge.

Roth, W.-M., \& Radford, L. (2010). Re/thinking the zone of proximal development (symmetrically). Mind, Culture, and Activity, 17, 299-307.

Roth, W.-M., \& Thom, J. (2009). Bodily experience and mathematical conceptions: From classical views to a phenomenological reconceptualization. Educational Studies in Mathematics, 70, 175-189.

Roth, W.-M., \& Thom, J. (2009). The emergence of 3d geometry from children's (teacher-guided) classification tasks. Journal of the Learning Sciences, 18, 45-99.

Selting, M., Auer, P., Barden, B., Bergmann, J., Couper-Kuhlen, E., Günthner, S., Meier, C., Quasthoff, U., Schlobinski, P., \& Uhmann, S. (1998). Gesprächsanalytisches Transkriptionssystem [Conversation analytic transcription system]. Linguistische Berichte, 173, 91-122.

Vološinov, V. N. (1930). Marksizm i folosofija jazyka: osnovye problemy sociologičeskogo metoda b nauke o jazyke [Marxism and the philosophy of language: Main problems of the sociological method in linguistics]. Leningrad, USSR: Priboj.

Vygotskij, L. S. (2005). Psyxhologija razvitija čeloveka [Psychology of human development]. Moscow, Russia: Eksmo.

Vygotsky, L. S. (1978). Mind in society: The development of higher psychological processes. Cambridge, MA: Harvard University Press.

Yackel, E., Gravemeijer, K., \& Sfard, A. (2011). A journey in mathematics education 
research. Dordrecht, The Netherlands: Springer.

\section{Appendix: transcription conventions}

The transcription conventions are those of standard conversation analysis enhanced for the transcription of prosodic features (Selting et al. 1998). Unless modified, all words are written with small letters.

\begin{tabular}{|c|c|c|c|}
\hline Notation & & Description & Example \\
\hline$(0.14)$ & & Time without talk, in seconds & okay. $(0.24) \mathrm{OH}$ \\
\hline$(\cdot)$ & & $\begin{array}{l}\text { Period in parentheses marks a } \\
\text { hearable (micro-) pause less } \\
\text { than } 0.1 \text { seconds long }\end{array}$ & NO. $(\cdot)$ <<assertive>you \\
\hline (??) & & $\begin{array}{l}\text { Question marks in parentheses } \\
\text { indicate (approximate) number } \\
\text { of undecipherable words }\end{array}$ & and (??) the square \\
\hline ( (turns) & & $\begin{array}{l}\text { Verbs and descriptions in double } \\
\text { parentheses are transcriber's } \\
\text { comments }\end{array}$ & ( (head sideward $))$ \\
\hline$::$ & & $\begin{array}{l}\text { Colons indicate lengthening of } \\
\text { phoneme, about } 1 / 10 \text { of a } \\
\text { second per colon }\end{array}$ & $\mathrm{U}:: \mathrm{M}:::$ : \\
\hline [ ] & & $\begin{array}{l}\text { Square brackets in consecutive } \\
\text { lines indicate overlap }\end{array}$ & $\begin{array}{l}\mathrm{J}: \text { wa }[\text { xes. }] \\
\mathrm{C}:[\mathrm{wAX} ?] \quad(0.93)\end{array}$ \\
\hline$<\mathrm{p}>\quad>$ & & $\begin{array}{l}\text { Piano, lower than normal speech } \\
\text { volume }\end{array}$ & $\begin{array}{l}<<\text { p }>\text { like we get hot air } \\
\text { from. }>\end{array}$ \\
\hline$<<f>$ & $>$ & Forte, louder than normal & $<<$ f $>$ whAT $>(0.23)$ makes \\
\hline$<<f f>$ & $>$ & $\begin{array}{l}\text { Fortissimo, much louder than } \\
\text { normal }\end{array}$ & $<<f f>[n o] .>$ \\
\hline$<<\mathrm{pp}>$ & $>$ & $\begin{array}{l}\text { Pianissimo, a lot lower than } \\
\text { normal speech volume, almost } \\
\text { inaudible }\end{array}$ & $<<$ pp $>$ kay.> \\
\hline$<<a l l>>$ & $>$ & $\begin{array}{l}\text { Allegro, words are uttered with } \\
\text { faster than normal speed }\end{array}$ & $<<$ all>okay?> \\
\hline$<<$ dim $>$ & $>$ & $\begin{array}{l}\text { Diminuendo, decreasing speech } \\
\text { intensity }\end{array}$ & $\begin{array}{l}<<\text { dim }>\text { just; just lay } \\
\text { this one down }>\end{array}$ \\
\hline$<<$ len $>$ & $>$ & Lento, slower than normal & $\begin{array}{l}<<l e n>\text { and what do you } \\
\text { mean by the same. }>\end{array}$ \\
\hline$<<$ rall $>$ & $>$ & Rallentando, slowing down & $<<$ rall $>$ are the same $>$ \\
\hline$<<\operatorname{acc}>$ & $>$ & Accelerando, speeding up & $<<$ acc $>$ they look a little \\
\hline
\end{tabular}


